\title{
Light Enhanced Calcification in Hermatypic Corals: New Insights from Light Spectral Responses
}

\author{
Itay Cohen ${ }^{1,2 *}$, Zvy Dubinsky ${ }^{3}$ and Jonathan Erez ${ }^{2}$ \\ ${ }^{1}$ Department of Oceanography, The Institute of Earth Sciences, The Hebrew University of Jerusalem, Jerusalem, Israel, ${ }^{2} \mathrm{H}$. \\ Steinitz Marine Biology Laboratory, The Interuniversity Institute for Marine Sciences, Eilat, Israel, ${ }^{3}$ The Mina and Everard \\ Goodman Faculty of Life Sciences, Bar-Ilan University, Ramat-Gan, Israel
}

OPEN ACCESS

Edited by:

Noga Stambler,

Bar-llan University, Israel

Reviewed by:

Susana Enríquez,

Universidad Nacional Autonoma de

Mexico, Mexico

David Suggett,

University of Technology Sydney,

Australia

Denis Allemand,

Centre Scientifique de Monaco,

Monaco

*Correspondence: Itay Cohen

2itaycohen@gmail.com

Specialty section: This article was submitted to

Coral Reef Research,

a section of the journal

Frontiers in Marine Science

Received: 28 June 2015 Accepted: 21 December 2015

Published: 11 January 2016

Citation:

Cohen I, Dubinsky Z and Erez J (2016) Light Enhanced Calcification in Hermatypic Corals: New Insights from

Light Spectral Responses.

Front. Mar. Sci. 2:122

doi: 10.3389/fmars.2015.00122
Light enhanced calcification (LEC) is a well-documented phenomenon in reef-building corals. The main mechanism proposed for LEC is that photosynthetic $\mathrm{CO}_{2}$ uptake by the algal symbionts elevates the $\mathrm{pH}$ and thus enhances calcification. We evaluated the role of light and of photosynthesis on calcification by assessing the response of the corals Porites lutea and Acropora variabilis to different components of the light spectrum. Calcification and photosynthesis of both species decreased under "lagoon" blue, green and red light (peaks at 500,550, and $600 \mathrm{~nm}$, respectively). However, blue light (peak at $455 \mathrm{~nm}$ ) enhanced calcification rates of $P$. lutea and $A$. variabilis (up to 4.1 - and 10.5-fold of dark values, respectively) reaching levels comparable to those measured under full spectrum illumination. However, contrary to our expectations, photosynthetic oxygen production was considerably reduced under blue light, to the extent that it remained below the compensation point even under illumination as high as $400 \mu \mathrm{mol}$ photons $\mathrm{m}^{-2} \mathrm{~s}^{-1}$. It is the first time that a direct effect of light not mediated by the photosynthetic process has been demonstrated to trigger LEC in corals. We propose that blue light signaling, and animal receptors thereof may be involved in the enhancement of calcification by hermatypic corals.

Keywords: calcification, photosynthesis, spectrum, blue light receptors, corals, signal transduction

\section{INTRODUCTION}

Light environment can influence the calcification physiology, general metabolism, and overall ecological success of hermatypic, reef-building, corals (Falkowski et al., 1984). This can be primarily attributed to photosynthesis of zooxanthellae, symbiotic unicellular algae harbored in large quantities in the endodermal cells of the coral host. Goreau (1959) first demonstrated that corals containing zooxanthellae typically exhibit higher calcification rates when illuminated. This phenomenon has become commonly accepted and described as Light Enhanced Calcification (LEC) in many later studies (Reviewed by Gattuso et al., 1999). LEC however is not unique to hermatypic corals. It has also been shown to be important for calcareous macroalgae (e.g., Gao et al., 1993), coccolithophores (e.g., Paasche, 1966), symbiont bearing benthonic and planktonic foramnifera (e.g., Erez, 1983; Ter Kuile et al., 1989a), and seagrass (Enríquez and Schubert, 2014). LEC enables coral reefs to thrive in shallow, well-lit waters, and may help alleviate the long-term effects of ocean acidification (Suggett et al., 2013). However, anthropogenic activities, such as dredging and eutrophication, coupled with phytoplankton blooms are altering the penetration of visible light through the water column. 
Various studies have been designed to understand the mechanisms of LEC and its relation to zooxanthellae photosynthesis. Some of these studies report that LEC in corals was reduced by the photosynthetic inhibitor DCMU, while dark calcification was unaffected (Vandermeulen et al., 1972; Barnes, 1985). It should be noted however that the DCMU concentrations used (i.e., $5 \times 10^{-4} \mathrm{M}$ ) were well above those of botanical studies $\left(<14 \times 10^{-6} \mathrm{M}\right)$ (Slesak et al., 2003; Wagner et al., 2004). Barnes (1985) used a range of DCMU concentrations and still arrived to the same conclusions although concentration of $10^{-7} \mathrm{M}$ decreased photosynthesis below the compensation point while LEC was unaffected (see Table 1 in Barnes, 1985). LEC was indeed reduced significantly in bleached corals (Goreau, 1959; Colombo-Pallotta et al., 2010), suggesting zooxanthellae are essential for calcification. However, Rinkevich and Loya (1984) observed that illuminating a small area of a coral tissue with optic fiber does not enhance its $\mathrm{Ca}^{45}$ uptake and concluded that calcification is repressed by the lack of oxygen in the dark, rather than enhanced by light. When oxygen levels are experimentally increased, dark calcification of bleached (Colombo-Pallotta et al., 2010) and non-bleached (Wijgerde et al., 2012a) corals increases. In addition to oxygen and energy, photosynthetic products may be used as precursors for biosynthesis of organic matrix embedded in the skeleton (Pearse and Muscatine, 1971). However, it must still be noted that LEC is mainly attributed to the photosynthetic uptake of $\mathrm{CO}_{2}$, which can increase the carbonate ion concentration and facilitates precipitation of $\mathrm{CaCO}_{3}$ under photosynthetic mediated elevation of $\mathrm{pH}$ values according to Equation (1) (Goreau, 1959; Allemand et al., 1998):

$$
\begin{array}{r}
\mathrm{Ca}^{2+}+2 \mathrm{HCO}_{3}^{-} \stackrel{\text { Calcification }}{\longrightarrow} \mathrm{CaCO}_{3} \downarrow+\mathrm{H}^{+}+\mathrm{HCO}_{3}^{-} \rightarrow \\
\mathrm{CaCO}_{3} \downarrow+\mathrm{CO}_{2}+\mathrm{H}_{2} \mathrm{O}
\end{array}
$$

The general concept that in hermatypic coral- calcification and photosynthesis are closely interrelated, includes several incongruities. For example, zooxanthellae and calcification sites are separated by the mesoglea and 2 cell layers $(25 \mu \mathrm{m}$ apart) (Gattuso and Buddemeier, 2000). Another example is the fast calcification in the presence of only a few zooxanthellae in the white tips of many corals (e.g., Pearse and Muscatine, 1971). But also calcification of a whole coral specimens can be decouple from photosynthesis (Schneider and Erez, 2006; Cohen and Dubinsky, 2015).

Regardless of the coupling between calcification and photosynthesis, several studies suggest that calcification can be directly enhanced by light. Al-Horani et al. (2003a,b) using microsensors, observed that $\mathrm{pH}$ and $\mathrm{Ca}^{2+}$ in the calcifying fluid increases in the light. It has also been suggested that illumination can stimulate the influx of dissolved inorganic carbon (DIC) and $\mathrm{Ca}^{2+}$ toward the calicoblastic layer, facing the extracellular calcifying fluid (Mueller, 1984; Furla et al., 2000). These studies proposed that light could activate the $\mathrm{Ca}^{2+} / \mathrm{H}^{+}$antiporter $\mathrm{Ca}^{2+}$-ATPase. To test that hypothesis, Ip et al. (2015) showed that the activity of $\mathrm{Ca}^{2+}$-ATPase after $12 \mathrm{~h}$ of illumination was higher in the inner mantle (at the site of calcification) than in the outer mantle of the giant clam Tridacnas uamosa. However, light sensitive domain was not yet described for this pump.

In Anthozoa, to which all corals belong, photoreception is acquired by photosensitive extraocular proteins (Wolken and Mogus, 1979). These proteins are photoreceptors, whose activity can be detected by electrophysiological techniques, found both solitarily or in clusters, but are not organized into complex organs (Reviewed by Taddei-Ferretti and Musio, 2000). Such photoreceptors were discovered in several Acropora $s p$. corals and identified as cryptochromes and opsins, which absorbs mainly blue light (Levy et al., 2007; Mason et al., 2012). Furthermore, corals express rhodopsins and melanopsins photoreceptors (Gorbunov and Falkowski, 2002; Anctil et al., 2007; Vize, 2009) with a maximal sensitivity in blue light. These photoreceptors transfer signals via calcium as second messenger in many marine invertebrates (Yarfitz and Hurley, 1994; Vize, 2009). Blue light signaling is known for many cellular processes (reviewed by Shimazaki et al., 2007), and via multiple phototransduction pathways are responsible for many physiological processes of the coral host (Gorbunov and Falkowski, 2002; Levy et al., 2003; Hilton et al., 2012; Mason et al., 2012). But could this mechanism also be the connection between light and calcification? If LEC is indeed directly stimulated by light-the effect of spectrum would provide insight into the role of photoreceptors in this process. The response of corals at different spectra was previously determined for calcification via axial growth rates (Kinzie et al., 1984; Kaniewska et al., 2009), and for photosynthesis of isolated zooxanthellae via carbon assimilation (Halldal, 1968) or oxygen evolution (Scott and Jitts, 1977). Yet, simultaneous responses of calcification and photosynthesis to different spectra were determined only for coccolith formation of the single-celled algae Coccolithus huxleyi (Paasche, 1966). In the present study we carried out a light spectral study of photosynthesis and calcification on two abundant and representative corals $A$. variabilis and $P$. lutea. The simultaneous responses of calcification and photosynthesis at different wavelengths within the visible spectra might elucidate the extent to which these two processes are coupled and can provide us the opportunity to reevaluate previously accepted LEC mechanisms using non-intrusive methods.

\section{MATERIALS AND METHODS}

\section{Coral Collection and Maintenance}

Four fragments from each of four different colonies of the branching coral A. variabilis (Ehrenberg, 1834) and five whole colonies (surface area of $65-80 \mathrm{~cm}^{2}$ ) of the massive coral $P$. lutea (Milne-Edwards and Haime, 1851) were collected from a shallow reef (2-6 m depht) located in the Gulf of Eilat $\left(29^{\circ} 30^{\prime} \mathrm{N}\right.$, $34^{\circ} 56^{\prime} \mathrm{E}$ ). All P. lutea (yellow) colonies and A. variabilis (brown) fragments exhibited similar color morphs. Two weeks prior to the experiment, the fragments and colonies were glued onto bottle caps using Propoxy $20^{\mathrm{TM}}$ and were placed in situ on a submerged table located in front of the Inter University Institute (IUI) in Eilat at depth of $6 \mathrm{~m}$. 


\section{Incubation in Metabolic Chambers and Sampling}

Rates of calcification and photosynthesis were measured under four different visible spectral wavebands in comparison to a full spectrum as a control and to dark calcification and respiration. Under each waveband, the corals went through a series of incubations under different irradiance intensities. The coral specimens were kept at their natural habitat at $6 \mathrm{~m}$ depth between measurements and were retrieved within $2 \mathrm{~h}$ before the first incubation in the laboratory each day. That protocol guarantees that the corals were naturally fed between experiments.

Seawater was collected from $1 \mathrm{~m}$ depth at the beginning of each day in collapsible plastic bags to fill the chambers for the incubation. As we poured water from the collapsible bags, it was reshaped according to the amount of water left, minimizing evaporation in the seawater reservoir between incubations. Blank incubations without corals were measured under dark and full light spectrum at 400 and $800 \mu \mathrm{mol}$ photons $\mathrm{m}^{-2} \mathrm{~s}^{-1}$, the changes in seawater alkalinity and $\mathrm{O}_{2}$ after $1 \mathrm{~h}$ were similar to the average difference between duplicates of all incubations in this study: $0.002 \mu \mathrm{mol} \mathrm{Kg}{ }^{-1}$ for alkalinity and $2.8 \mu \mathrm{mol} \mathrm{L}^{-1}$ for $\mathrm{O}_{2}$. These values are expected for the very low concentrations of plankton in the oligotrophic seawater in the Gulf of Eilat (Khalil and El-Rakman, 1997) and are negligible compared to two orders of magnitude higher changes in both parameters after coral incubations.

The coral specimens were placed in a sealed acrylic metabolic chamber of a volume of $500 \mathrm{ml}$ and magnetic stirring bar circulated the water in the chamber. The volume of $A$. variabilis and $P$. lutea specimens ranged between 7.5 and $11 \mathrm{ml}$ and between 35 and $83 \mathrm{ml}$, respectively. The metabolic chambers were immersed in a 20 liter thermostatted tub controlled with NESLAB, RTE 210 circulating bath to $23^{\circ} \mathrm{C}$, according to the average temperature of the sea (measured with thermometer) during the months of the experiments (Feb: daily variations of $21.9-22.9^{\circ} \mathrm{C}$ to May: $22.6-24.3^{\circ} \mathrm{C}$ of 2011 ). Light levels were controlled by increasing the distance of a Metal halide lamp (Osram powerstar HQI-BT 400K, 5000K, Germany) from the incubated corals. Spectral manipulation was achieved by covering the chambers with one of four polycarbonate filters (Lee Filters, Bright red 026, Dark green 124, Lagoon blue 172, Deep blue 120 (referred as blue throughout the manuscript), see Figure 1 for their spectra). Water was drawn from the reservoir at the onset of the incubation and from the experimental chamber after $1 \mathrm{~h}$. According to Wijgerde et al. (2012b) calcification is at its maximum under oxygen levels ranging between 75 and $150 \%$. We used a short $(1 \mathrm{~h})$ incubations to avoid exceeding these values. Duplicate samples were slowly injected into two $\sim 60 \mathrm{ml}$ glass Winkler bottles for oxygen determinations and into a $100 \mathrm{ml}$ brown glass bottle for alkalinity titration (Schneider and Erez, 2006). The bottles and bottle caps were washed with the sampled seawater three times before filling. Oxygen concentration was determined as soon as the incubation ended by first adding reagents for Winkler titration (Winkler, 1888). We adjusted the Winkler titration endpoint detection by using automatic titrator (702SM titrino, Methrom, Swiss) and our

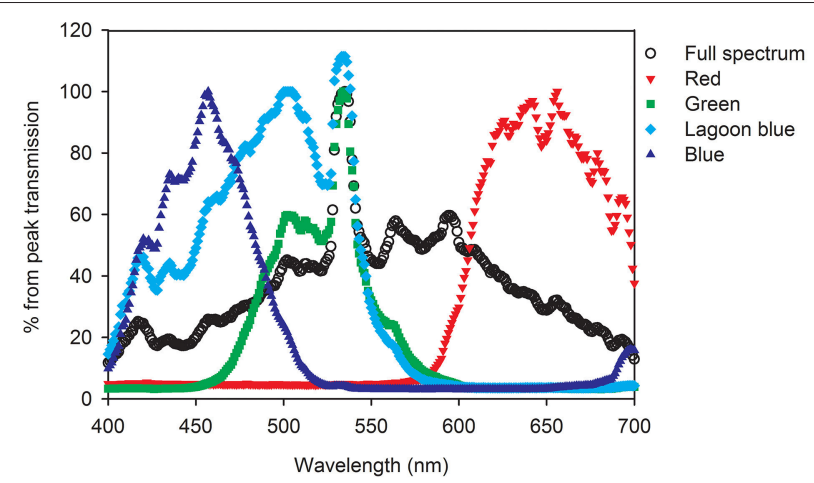

FIGURE 1 | Spectrum of the Metal halide lamp (Full spectrum control) and the transmission spectra through red, green, "lagoon" blue, or blue filters, calculated as percent relative to the peak $(100 \%)$.

precision error between duplicates was $\pm 1.01 \%$. For the alkalinity measurements, sea water samples were kept at $4^{\circ} \mathrm{C}$ for a maximum of 4 days, after which these samples were slowly heated to $25^{\circ} \mathrm{C}$ and filtered $(0.2 \mu \mathrm{m})$ and duplicate or triplicate samples of $\sim 30 \mathrm{ml}$ were accurately weighed before the titration with HCL $0.5 \mathrm{~N}$ (800 Dosino, Methrom, Swiss). The pH electrode (Methrom) was calibrated daily with $\mathrm{pH}$ buffers 4,7 , and 9.14 (Radiometer analytical) and our precision error between duplicates was $\pm 0.08 \%$.

The results were normalized to the surface area of coral fragments. A. variabilis fragments were sacrificed for the paraffin wax method described by Stimson and Kinzie (1991). The surface area of $P$. lutea was calculated as half ellipsoid from the width $\left(\mathrm{r}_{1}\right)$, length $\left(\mathrm{r}_{2}\right)$, and height $(\mathrm{h})$ of each colony, measured with a caliper according to Equation (2).

$$
\begin{aligned}
& \text { Surface area of half ellipsoid }= \\
& \frac{2 \pi\left\{\left[\left(\mathrm{r}_{1} \times \mathrm{r}_{2}\right)^{1.6075}+\left(\mathrm{r}_{1} \times \mathrm{h}\right)^{1.6075}+\left(\mathrm{r}_{2} \times \mathrm{h}\right)^{1.6075}\right]\right\}^{\frac{1}{1.6075}}}{3}
\end{aligned}
$$

Net photosynthesis $(\mathrm{Pn})$ and respiration $(\mathrm{R})$ rates (Equation 3 ) were calculated from changes in oxygen concentration. Calcification rates (Equation 4) were calculated from changes in total alkalinity $\left(\mathrm{T}_{\mathrm{A}}\right)$ multiplied by the density of seawater $(1.028$ $\mathrm{L} \times \mathrm{Kg}^{-1}$ ) and by 1000 to convert from mmol to $\mu \mathrm{mol}$, divided by 2 because every $2 \mathrm{H}^{+}$ions titrated accounts for one $\mathrm{CaCO}_{3}$ precipitated. Both parameters were normalized to the volume $(\mathrm{V})$ of the metabolic chamber minus the volume of the specimen divided by the surface area of the specimen and incubation time (t) of $1 \mathrm{~h}$.

$$
\begin{aligned}
& \text { Pn or } \mathrm{R}\left(\mu \mathrm{mol} \mathrm{O} 2 \mathrm{~cm}^{-2} \mathrm{~h}^{-1}\right)= \\
& \frac{(\mathrm{O} 2 \text { chamber }-\mathrm{O} 2 \text { reservoir }) \times \mathrm{V}(\text { chamber }- \text { specimen })}{\text { surface area } \times \mathrm{t}(1 \mathrm{~h})}
\end{aligned}
$$




$$
\begin{aligned}
& \begin{array}{r}
\text { Calcification }\left(\mu \mathrm{molCaCO} 3 \mathrm{~cm}^{-2} \mathrm{~h}^{-1}\right)= \\
\left(\mathrm{T}_{\mathrm{A}} \text { reservoir }-\mathrm{T}_{\mathrm{A}} \text { chamber }\right) \times \mathrm{V}(\text { chamber }- \text { specimen }) \\
\times 1.028 \times 1000
\end{array} \\
& 2 \times \text { surface area } \times \mathrm{t}(1 \mathrm{~h})
\end{aligned}
$$

The relationships of photosynthesis and calcification vs. light intensities were fitted for all treatments using a hyperbolic tangent function (Equations 5, 6, Chalker, 1981). The maximal rate of net photosynthesis $\left(\mathrm{P}_{\mathrm{n}} \max \mu \mathrm{mol} \mathrm{O}_{2} \quad \mathrm{~cm}^{-2} \mathrm{~h}^{-1}\right)$, calcification (Gmax $\mu$ mol $\mathrm{CaCO}_{3} \mathrm{~cm}^{-2} \mathrm{~h}^{-1}$ ), compensation point of photosynthesis $\left(E_{c} \mu\right.$ mol photons $\left.\mathrm{m}^{-2} \mathrm{~s}^{-1}\right)$, and the optimal irradiance of both photosynthesis and calcification $\left(\mathrm{E}_{\mathrm{k}} \mu \mathrm{mol}\right.$ photons $\mathrm{m}^{-2} \mathrm{~s}^{-1}$ ) were derived from non linear sum of squares (nls) model using the statistical program Rstudio (version 2.15.0). We also used $t$-test to assess the significance by which every derived parameter adheres to the fitted curve. Data points from all repeats were fitted to model one curve (as opposed to separate curves for each repeat) in order to increase the accuracy and significance of the values, however statistical differences between treatments is not possible.

$$
\begin{aligned}
& \text { Pn (net photosynthesis) }= \\
& \qquad \operatorname{Pmax} \times \frac{\text { hyperbolic tangent } \times(\text { Irradiance })}{\mathrm{Ek}}(5) \\
& \text { Calcification }=\text { Gmax } \times \frac{\text { hyperbolic tangent } \times(\text { Irradiance })}{\mathrm{Ek}}(6)
\end{aligned}
$$

\section{Light and Spectral Measurements}

Light intensity under the full visible spectrum $(400-700 \mathrm{~nm})$ and each of the four discrete bandwidths was measured with a LI190 SA quantum sensor (Li-Cor, Inc., Lincoln, NE). The LI-190 SA, connected to a Li-Cor LI-1000 data-logger, measures light as an integrated value of all photons impinging on the sensor per second ( $\mu$ mol photons $\mathrm{m}^{-2} \mathrm{~s}^{-1}$ ). Photon flux is therefore similar for all spectral wavebands.

The control and experimental treatments (the four wavebands) were measured using an USB2000 Fiber Optic Spectrometer. The USB2000 Fiber Optic Spectrometer was attached next to the LI-190 SA quantum sensor to measure the spectrum under all light intensities used for the incubations (Figure 1). By restricting the wavelength range, a large fraction of the light is absorbed (especially using the blue filter). The maximal light intensity was therefore limited to $400 \mu \mathrm{mol}$ photons $\mathrm{m}^{-2} \mathrm{~s}^{-1}$ for blue light and $800 \mu \mathrm{mol}$ photons $\mathrm{m}^{-2}$ $\mathrm{s}^{-1}$ for the other wavebands. The absorbance of each filter was also described using a spectrophotometer (Ultrospec 2100 pro, Amersham Pharmacia Biotech, NJ) and the percentage of transmittance of the filters across the $300-800 \mathrm{~nm}$ range were calculated (colored graph in Figure 1).

\section{Statistics}

We used SigmaPlot 10 (Systat Software Inc., Chicago, IL) for the graphic presentation and SPSS 16.0 (SPSS Inc., Chicago, IL) and $\mathrm{R}$ program to assess statistical significance. When Shapiro-Wilk
Normality Test failed, root square transformation was used to verify normal distribution of the data, allowing the use of parametric statistical tests. We evaluated the significance by which changes in light intensity and spectral quality affected calcification and photosynthesis using One-way ANOVA. The fitting of $\mathrm{P}_{\mathrm{n}} \max , \mathrm{Gmax}$, and $\mathrm{E}_{\mathrm{k}}$ to the hyperbolic tangent model was calculated with $t$-test. We also used One-way ANOVA and linear regression to evaluate the slope and intercept differences between treatments when calcification ( $\mathrm{Y}$ axis) was plotted against photosynthesis (X axis). The ANOVA was followed by pairwise comparisons of estimated marginal means (Bonferroni adjusted) and considered significant at $P<0.05$.

\section{RESULTS}

Calcification and photosynthesis of $P$. lutea and $A$. variabilis both increased when illuminated with full spectrum light as expected. Significant increases in calcification $(P<0.01)$ and oxygen production $(P<0.001)$ of $A$. variabilis was observed at $200 \mu \mathrm{mol}$ photons $\mathrm{m}^{-2} \mathrm{~s}^{-1}$ compared to dark treatments (Figure 2). In $P$. lutea these processes seems to decouple slightly in response to light intensity. Calcification, similar to A. variabilis, was significantly enhanced by $200 \mu \mathrm{mol}$ photons $\mathrm{m}^{-2} \mathrm{~s}^{-1}(P<$ 0.05 ) of control light, however oxygen production was significant already at $75 \mu \mathrm{mol}$ photons $\mathrm{m}^{-2} \mathrm{~s}^{-1}(P<0.01)$ and began to saturate at an intensity higher than calcification $\left(\mathrm{E}_{\mathrm{k}}=\sim\right.$ 360 and $110 \mu \mathrm{mol}$ photons $\mathrm{m}^{-2} \mathrm{~s}^{-1}$, respectively; Figure 3). Maximal photosynthesis and calcification rates, in both species, were almost similar under control light (Table 1), however when illumination was restricted to the blue waveband calcification and photosynthesis clearly decoupled. Significant decreases in net photosynthesis under blue light were observed under all experimental intensities compared with full spectrum (75: $P<$ 0.05, 200: $P<0.01$, and $400 \mu \mathrm{mol}$ photons $\mathrm{m}^{-2} \mathrm{~s}^{-1}: P<$ 0.001 ), and remained below the compensation point for all light intensities. This was evidenced by the negative $\mathrm{P}_{\mathrm{n}} \max$ value of $P$. lutea. Photosynthesis of $A$. variabilis under blue light was calculated to reach compensation at the maximal experimental illumination $\left(\mathrm{E}_{\mathrm{c}}=\sim 400 \mu \mathrm{mol}\right.$ photons $\mathrm{m}^{-2} \mathrm{~s}^{-1}$ ), resulting in $\mathrm{P}_{\mathrm{n}}$ max of $0 \mu \mathrm{mol} \mathrm{O} \mathrm{cm}^{-2} \mathrm{~h}^{-1}$. Photosynthesis under blue light also compensated at lower intensity compared to the control and the rest of the treatments. Conversely, calcification of both corals was significantly higher than in the dark when illuminated with $=200 \mu \mathrm{mol}$ photons $\mathrm{m}^{-2} \mathrm{~s}^{-1}$ of blue light $(P<0.01)$ and was at similar rates as the control under all intensities. The light to dark calcification ratios of $A$. variabilis under $400 \mu \mathrm{mol}$ photons $\mathrm{m}^{-2}$ $\mathrm{s}^{-1}$ of control and blue light were 8.4 and 10.5 , respectively; while lower ratios were observed in $P$. lutea (3.4 and 4.5). In both cases, calcification under blue light exceeds even these of the control, please note however that light to dark calcification ratio increased to 4.8 in $P$. lutea when control light intensity was elevated to $800 \mu \mathrm{mol}$ photons $\mathrm{m}^{-2} \mathrm{~s}^{-1}$. Unfortunately, illumination under blue light was limited to $400 \mu \mathrm{mol}$ photons $\mathrm{m}^{-2} \mathrm{~s}^{-1}$ and a potential increase in calcification beyond this light level could not be measured.

When A. variabilis fragments were incubated under "lagoon" blue, green, and red spectral ranges both calcification and 

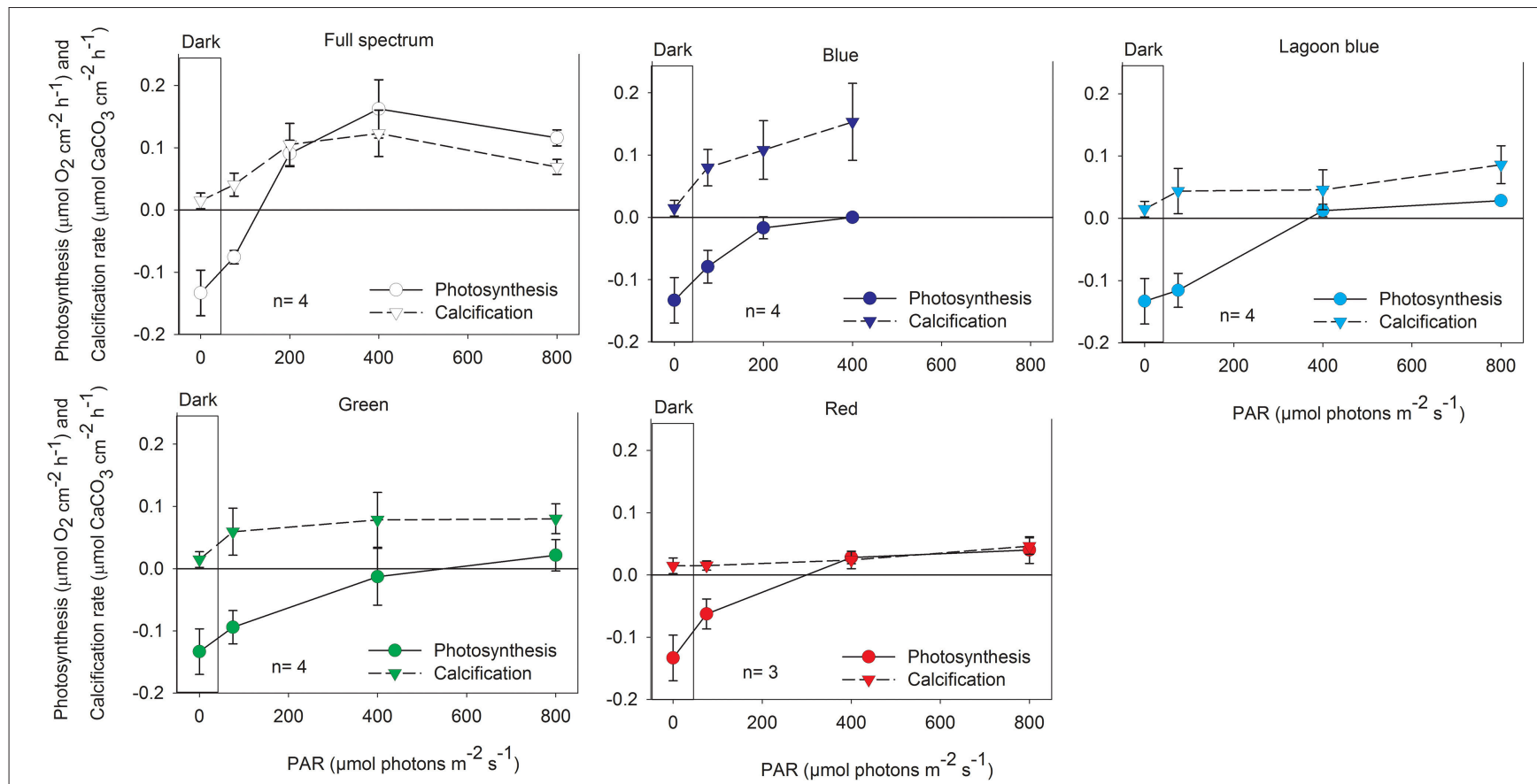

FIGURE 2 | Net photosynthesis and calcification (mean \pm SD) of the coral A. variabilis exposed to increasing intensities of control, full spectrum, blue, lagoon blue, green, or red light.

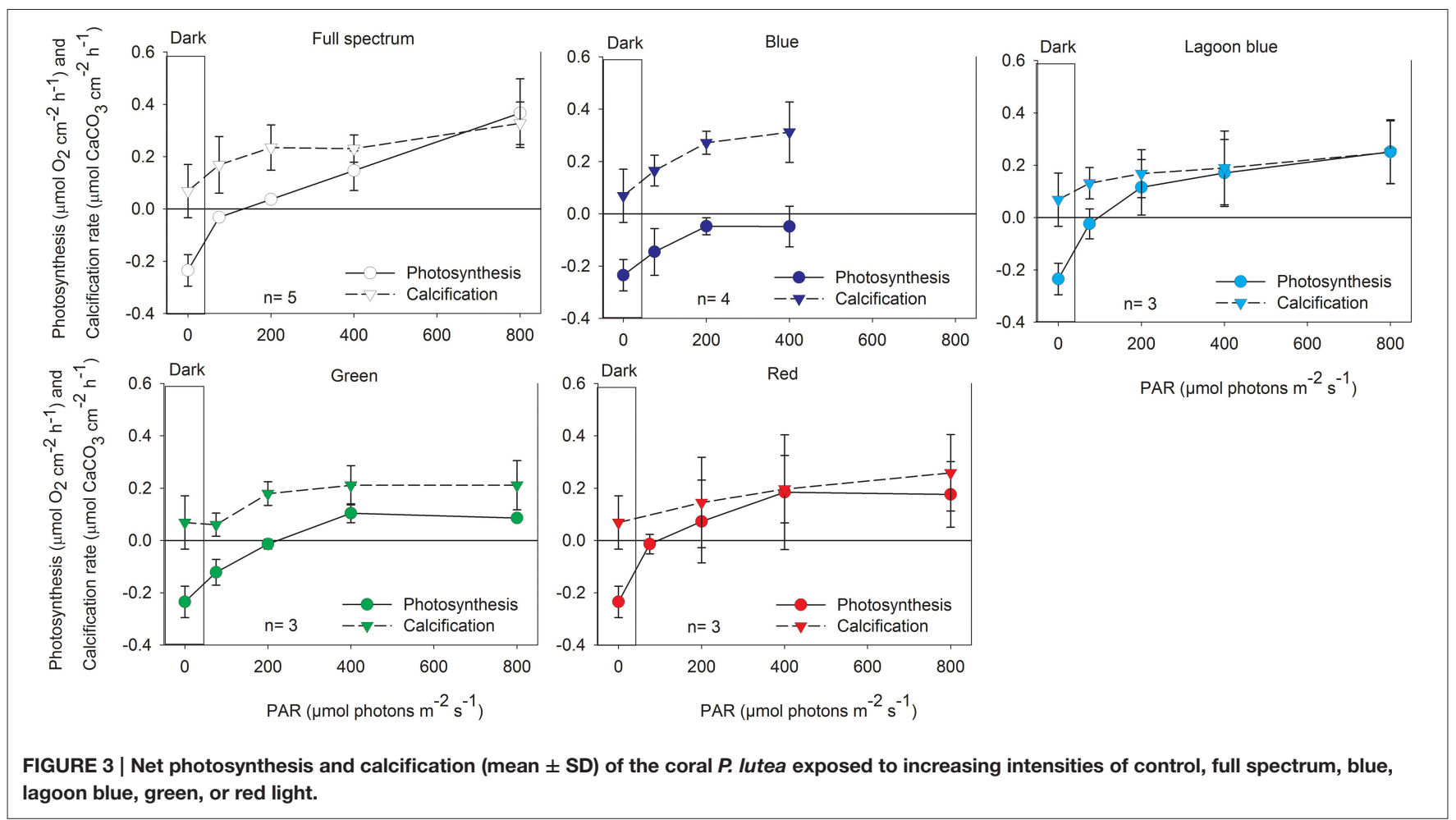

photosynthesis were inhibited, calcification was not significantly higher than dark and photosynthesis was significantly lower than control $(P<0.01$ in $200-400, P<0.05$ in $800 \mu \mathrm{mol}$ photons $\mathrm{m}^{-2} \mathrm{~s}^{-1}$ ). This was reflected by a vast increase in photosynthetic compensation and saturation intensity compared to full spectrum. While photosynthesis of $P$. lutea was also 
TABLE 1 | All replicates of $A$. variabilis and of $P$. lutea were combined to calculate a single hyperbolic tangent function (Chalker, 1981) for each color.

\begin{tabular}{|c|c|c|c|c|c|c|}
\hline & \multicolumn{3}{|c|}{ Net photosynthesis } & \multicolumn{3}{|c|}{ Calcification } \\
\hline & $\mathrm{E}_{\mathrm{c}}$ & $E_{k}$ & $P_{n} \max$ & $E_{k}$ & Gmax & LEC \\
\hline \multicolumn{7}{|c|}{ ACROPORA VARIABILIS } \\
\hline Control & 102 & 207 & 0.15 & 134 & 0.1 & 8.4 \\
\hline Blue & 388 & 170 & 0 & 195 & 0.14 & 10.5 \\
\hline Lagoon blue & 396 & 370 & 0.04 & NS & 0.08 & 3.1 \\
\hline Green & 488 & 437 & 0.02 & NS & 0.06 & 5.3 \\
\hline Red & 250 & 391 & 0.05 & NS & NS & 1.6 \\
\hline \multicolumn{7}{|c|}{ PORITES LUTEA } \\
\hline Control & 170 & 368 & 0.31 & 112 & 0.28 & 3.4 \\
\hline Blue & Below & 142 & -0.05 & 127 & 0.31 & 4.5 \\
\hline Lagoon blue & NS & 317 & 0.04 & NS & 0.26 & 2.8 \\
\hline Green & 206 & 228 & 0.1 & 190 & 0.22 & 3.1 \\
\hline Red & 142 & 125 & 0.17 & NS & NS & 2.9 \\
\hline
\end{tabular}

Maximal net photosynthesis $\left(P_{n} \max \mu \mathrm{mol} \mathrm{O}_{2} \mathrm{~cm}^{-2} h^{-1}\right.$ ) and calcification (Gmax $\mu \mathrm{mol}$ $\mathrm{CaCO}_{3} \mathrm{~cm}^{-2} \mathrm{~h}^{-1}$ ), light intensity ( $\mu \mathrm{mol}$ photons $\mathrm{m}^{-2} \mathrm{~s}^{-1}$ ) at the onset of saturation $\left(E_{k}\right)$ and at the compensation of photosynthesis $\left(E_{c}\right)$ were derived from the function. Only parameters that significantly (at least $P<0.05$ ) fits the model are shown (NS, not significant). When compensation is not reached $E_{C}$ is marked as Below. $L E C$ values are light (at $400 \mu \mathrm{mol}$ photons $\mathrm{m}^{-2} \mathrm{~s}^{-1}$ ) to dark calcification ratio as calculated from data in Figures 2, 3 decreased under these color treatments, such inhibition in calcification was less apparent.

When calcification is plotted against photosynthesis (Figure 4, Table 2), the $\mathrm{R}^{2}$ of the linear regression was as high in blue light and in most of the spectral treatments as in the control. This means that although photosynthesis of both species was inhibited substantially under blue light, it still responded to blue light intensity in parallel to calcification. It is clear from Figure 4A that all data points of blue light are above the 1:1 ratio of calcification: photosynthesis in both corals, whereas under control and the rest of the spectra these ratios are much lower than 1 and even decrease as light intensity increase. More importantly, under blue light calcification is very high, even higher than under full spectrum, while photosynthesis remains below the compensation point, meaning that $\mathrm{CO}_{2}$ production is higher than consumption (Figure 4B). The slopes indicate that for each mol $\mathrm{O}_{2}$ produced by $P$. lutea $1.3 \mathrm{~mol} \mathrm{CaCO}_{3}$ is precipitated under blue light about only 0.4 under control light. A similar trend is observed in A. variabilis, the linear regression slope doubles under blue light and decreases to half under the rest of the colors compared to the control. These slopes were found to be significantly different between colors $(P<0.01)$ in $P$. lutea but not in A. variabilis. Furthermore, in both corals the intercept with $\mathrm{Y}$ axis was significantly different between colors $(P<0.01)$. Using linear regression model on both corals, we rejected the
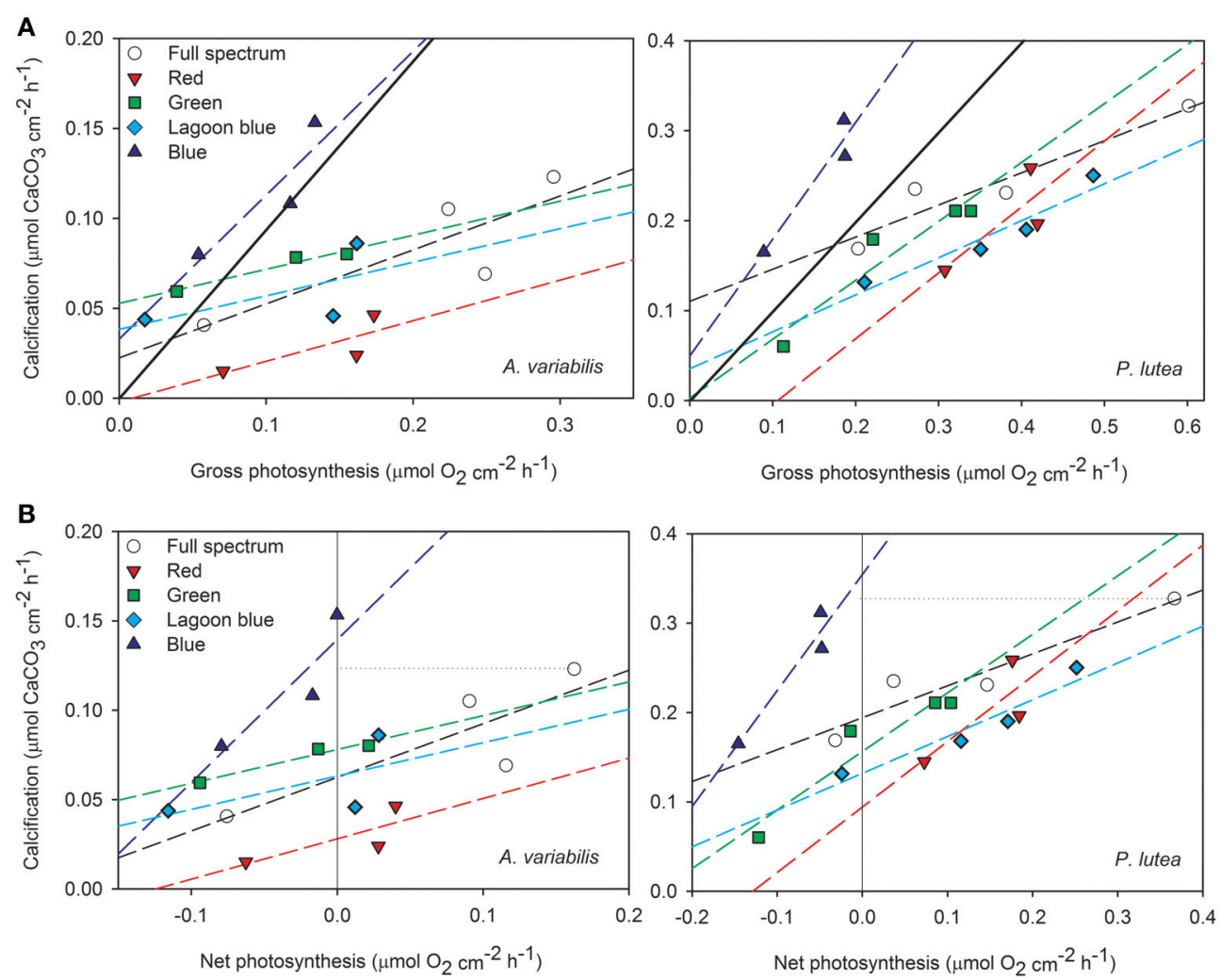

FIGURE 4 | Rates of calcification are plotted against (A) gross photosynthesis and (B) net photosynthesis of $\boldsymbol{A}$. variabilis and $\boldsymbol{P}$. Iutea in the four spectral ranges, including the full spectrum control. The diagonal full line marks the 1:1 ratio between the processes and the horizontal dotted line is drawn from the highest calcification rate under full spectrum for comparison with blue light. 
statistical hypothesis that the slopes are not significantly different from 1 in all colors except from the effect of red light on P. lutea. That means that there is no 1:1 ratio between calcification and photosynthesis under most light treatments.

\section{DISCUSSION}

It is well-documented that when stony corals are illuminated both calcification and photosynthesis are enhanced (Figures 2, 3; Goreau, 1959; Chalker, 1981; Chalker et al., 1985). However, many marine organisms (including deep dwelling corals) calcify at high rates in complete darkness (Roberts et al., 2006). Light can enhance calcification indirectly by increasing the photosynthesis of the symbionts (e.g., Goreau, 1959; Falkowski et al., 1984), however light may also enhance calcification directly in foraminifera and corals (e.g., Erez, 1983; Barnes, 1985; AlHorani et al., 2003a,b). We tested whether calcification of two hermatypic corals is activated by a specific waveband, and whether this waveband coincides with the action spectrum for photosynthesis of their symbionts. In both $P$. lutea and $A$. variabilis taken from a shallow reef $(6 \mathrm{~m})$, calcification and photosynthesis rates under red, green and the "lagoon" blue wavebands were lower than when exposed to the full visible spectrum (PAR) (Figure 5). However, under all intensities of blue light, photosynthesis remained below the compensation point and lower than under any of the other spectral domains,

TABLE 2 | Slopes and $R^{2}$ derived from a linear regression relationship between calcification and photosynthesis of the corals $P$. lutea and A. variabilis.

\begin{tabular}{llllll}
\hline & \multicolumn{2}{c}{ Porites lutea } & & \multicolumn{2}{c}{ Acropora variabilis } \\
\cline { 2 - 3 } & $\mathbf{R}^{\mathbf{2}}$ & Slope & & $\mathbf{R}^{\mathbf{2}}$ & Slope \\
\hline Control & 0.91 & 0.38 & & 0.76 & 0.34 \\
Blue & 0.99 & 1.32 & & 0.78 & 0.76 \\
Lagoon blue & 0.98 & 0.3 & & 0.38 & 0.19 \\
Green & 0.9 & 0.67 & & 0.95 & 0.19 \\
Red & 0.7 & 0.91 & & 0.62 & 0.22
\end{tabular}

while calcification was as high as under full light spectrum, i.e., maximal rate of LEC. These responses to different parts of the visible spectrum demonstrate that while photosynthesis is partially activated over a wide range of wavelengths, the activation of light-enhanced calcification is maximal in a narrow waveband of the blue range. When photosynthesis is below the compensation point, as under blue light, $\mathrm{CO}_{2}$ levels in the coral tissues increases, although at lower rates than in the dark. The significance of this finding is that LEC can proceed without $\mathrm{CO}_{2}$ removal due to the photosynthesis of the symbionts and its associated $\mathrm{pH}$ elevation as can be deduced from Equation (1). This main conclusion and its implications are discussed below. Given that $\mathrm{CO}_{2}$ removal is not the main cause for LEC what is the role of blue light in this process?

Absorption of blue light by the coral may be due to several blue light photoreceptors found in the coral host (Gorbunov and Falkowski, 2002; Levy et al., 2007). Also Stambler and Dubinsky (2005) showed that when corals are illuminated, blue light is effectively absorbed, in comparison to the rest of the spectra, except for the red light, which is absorbed mainly by the symbionts. The same pattern was also evident in several color morphs of Stylophora pistillata and Pocillopora damicornis (Stambler and Shashar, 2007). Levy et al. (2007) described the light responses of one of such photoreceptors, cryptochrome, in the coral Acropora millepora. The role of cryptochrome photoreceptors in the phototropism of higher plants is wellknown (Iino, 1990; Ahmad et al., 2002). Similarly, Kaniewska et al. (2009) suggested that axial growth toward blue light in the coral Acropora pulchra can be considered a phototropic response. We suggest that LEC in corals may receive cues controlling phototropism and directional growth, as in plants. However, the effect of blue light receptors on the physiology of calcification mechanisms in the coral host is yet unknown. Blue light seems to act as a signal for activation of proton pumps (e.g., Assmann et al., 1985; Shimazaki et al., 1986) and ion (cation and anion) channels (Zeiger et al., 1987; Cho and Spalding, 1996) that create electrochemical gradients rather than serve as an energy source. Electrochemical gradients in corals can increase the diffusive paracellular transport (Tambutté et al., 2012). These may also increase permeability of cell membrane, as is the case
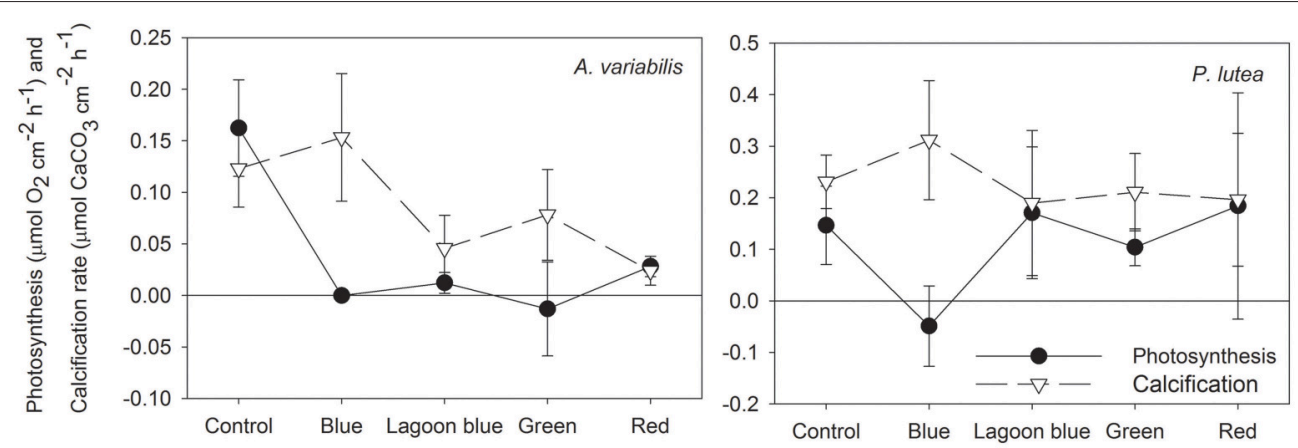

FIGURE 5 | Calcification and photosynthesis of $A$. variabilis and $P$. lutea illuminated with $400 \mu \mathrm{mol}$ photons $\mathrm{m}^{-2} \mathrm{~s}^{-1}$ of full spectrum, blue, "lagoon" blue, green, or red light. 
in the gastrointestinal tract of a number of animal species, for transcellular transport of ions (reviewed by Powell, 1981) that are required for calcification. Hilton et al. (2012) showed that elevating cytoplasmic $\mathrm{Ca}$ levels using ionomycin or thapsigargin in the dark, generates the same response in the proteome of azooxanthellate Acropora larvae as exposure to light. This implies that calcium acts as the second messenger of photoreceptors in corals. Given that light acts via calcium signals in other systems (e.g., Yarfitz and Hurley, 1994; Fain et al., 2010; Hilton et al., 2012) suggested that a similar mechanism is found in corals that is not mediated by the zooxanthellae.

Furthermore, a significant role in raising the $\mathrm{pH}$ at the calcification site was attributed to the activity of $\mathrm{Ca}^{2+}$-ATPase pumps located on the calicoblastic epithelium (Tambutte et al., 1996). Light activation of $\mathrm{Ca}^{2+}$-ATPase could best explain the high $\mathrm{Ca}^{2+}$ concentration found concomitantly to high $\mathrm{pH}$, at the site of calcification of illuminated G. fascicularis (AlHorani et al., 2003a). Al-Horani et al. (2003a) suggested that $\mathrm{Ca}^{2+}$-ATPase pumps are directly stimulated by light, however these pumps do not have light absorbing properties, hence, the only mechanism by which such pumps can be activated is by signal derived from photoreceptors. This activation can directly (without the mediation of photosynthesis) increase $\mathrm{pH}$ levels in the extracellular calcifying fluid of corals, which is of major importance for supporting enhanced calcification rates (Reviewed by Gattuso et al., 1999). Taylor et al. (2011) demonstrated with single cell imaging the important role of voltage gated $\mathrm{H}^{+}$channels in biomineralization of coccolithophores and the link between high $\mathrm{pH}$ and enhanced calcification in these organisms.

The increase in calcification as blue light increased up to saturation, and with minimal photosynthesis, suggests that LEC directly depends on light signaling and follows MichaelisMenten kinetics. This kinetics could represent the saturation of light absorption by photoreceptors or saturation of activity rates of ATPase pumps or any other protein that may be receiving light signals. Similar kinetics were shown for $\mathrm{Ca}^{2+}$ uptake by corals with increasing light intensities (Marshall and Clode, 2003), for calcification under increasing seawater $\mathrm{Ca}^{2+}$ concentration (Chalker, 1976; Gattuso, 1998) and for carbon uptake for calcification by symbiont-harboring foraminifera (Ter Kuile et al., 1989b).

The intensity level of illumination, specifically that of wavelengths in the blue range, was also found to stimulate tentacle retraction in hermatypic corals (Gorbunov and Falkowski, 2002; Levy et al., 2003). This occurs under very low light intensity, two orders of magnitude lower than the threshold needed to maintain photosynthetic electron flow. Moreover, tentacles did not retract at any other regions of absorption by photosynthetic pigments (Gorbunov and Falkowski, 2002), except for under higher intensities (Levy et al., 2003). Gorbunov and Falkowski (2002) illuminated areas in the tentacle lacking zooxanthellae, and observed similar retraction and suggested that photoreception is provided through a sensor in the invertebrate host cells. Such response to blue light was also observed in aposymbiotic cnidarians as Hydra (Taddei-Ferretti et al., 1992) and the sea anemone Metridium senile (North and
Pantin, 1958) providing further evidence that Antozoa can sense the intensity of light independently from the zooxanthellaemediated pathway. Passano and McCullough (1963) observed that retractions and elongations in Hydras occur in a repetitive pattern of $8-10$ cycles in $1 \mathrm{~h}$, and it is plausible that upon light, corals also have some periodic response of reopening the tentacles. We therefore suggest that such tentacle movement may influence the water circulation in the polyp cavity, which would provide fresh seawater with high concentrations of $\mathrm{Ca}^{2+}$ and DIC for calcification and photosynthesis. Both Levy et al. (2003) and Gorbunov and Falkowski (2002) showed that the action spectrum of tentacle retraction peaks at blue light $(480 \mathrm{~nm})$ although the time response varied markedly between coral species. This could be one of the factors influencing the variation in LEC between species, which was documented previously (Gattuso et al., 1999).

Morphologically, the distance among corallites and their diameter of the coral Acropora formosa increase in blue light compared with full spectrum leading to the enhanced growth (Rocha et al., 2014). Corallite growth of the hermatypic corals Pocillopora damicornis, Montipora verrucosa (Kinzie et al., 1984), and Acropora pulchra (Kaniewska et al., 2009) and specific growth rates of Galaxea fascicularis (Wijgerde et al., 2012b) were previously shown to be higher under blue light than under green or red light and similar to that sustained under the full spectrum controls. In these three studies corals were maintained under blue light for sufficiently long time (2-4 months) allowing for the symbionts to acclimate and possibly photosynthesize under these regimes, however photosynthesis and respiration rates were not measured. The enhancing effect of blue light on calcification may also explain why corals at $3 \mathrm{~m}$ grow only $\sim 3$ times faster than at the blue environment of $30 \mathrm{~m}$ depth, while PAR is $\sim 8$ times higher (Cohen and Dubinsky, 2015).

While calcification is mostly enhanced by blue light, photosynthesis was observed to be less efficient under that part of the spectrum. Similar to this study, shallow S. pistillata (Stambler, 1992; Mass et al., 2010), Favia sp. and Acropora sp. (Kuhl et al., 1995), Pocillopora damicornis, Millepora dichotoma, Fungia sp., and Platygyra sp. (Stambler, 1992) corals exhibited a clear reduction in their photosynthetic rates when illuminated with blue light. This reduction was probably due to a decrease in quantum yield of PSII fluorescence and sigma cross section of zooxanthellae under blue light as observed by Levy et al. (2006), implying that larger portion of the arriving photons is directed to non-photochemical quenching (NPQ). The deepoxidation cycle of xanthophylls, responsible in part for NPQ, consumes $\mathrm{O}_{2}$ and is activated at spectrum, which peaks at approximately $480 \mathrm{~nm}$, therefore possibly accounting for some $\mathrm{O}_{2}$ uptake under blue light illumination (Lee and Yamamoto, 1968). Xanthophyll interconversions can uptake $0.06 \mathrm{O}_{2} \mu$ moles per $\mu$ mole chlorophyll $\mathrm{h}^{-1}$ in spinach-leaf segments (Yamamoto et al., 1967). Such uptake might not be substantial in comparison to other oxygen utilizing processes in corals like respiration however, until being measured directly it should not be excluded.

In cyanophyta, it was noticed that the photons absorbed by chlorophylls (between $400-550$ and $650-700 \mathrm{~nm}$ ) are mostly 
dedicated to PSI while photons absorbed by the accessory pigments (550-660 nm) go to PSII (Jones and Myers, 1965). If indeed reaction centers in zooxanthellae share similar mechanism, blue light is absorbed preferentially by PSI that does not evolve $\mathrm{O}_{2}$. Light energy that activates PSI could still stimulate ATP synthesis by cyclic photophosphorylation. In this case, electrons are transferred back to $\mathrm{P}_{700}$ rather than passed on to NADP to form $\mathrm{NADPH}_{2}$ that is necessary for the operation of the Calvin cycle. As a result, cyclic photophosphorylation severely lowers total $\mathrm{CO}_{2}$ fixation (Schürmann et al., 1972) and may provide more DIC for calcification (Marubini and Thake, 1999) under the blue light. This would argue against the commonly accepted mechanisms by which $\mathrm{CO}_{2}$ fixation largely influences LEC (Goreau, 1959). Some of the ATP produced in cyclic photophosphorylation can also support calcification (Lucas and Knapp, 1997).

Furthermore, blue light can decrease net photosynthesis by causing enhanced respiration in corals (Kinzie and Hunter, 1987). Large increases in respiration of Chlorella pyrenoidosa after exposure to blue light led to substantial consumption of oxygen over the amount evolved photosynthetically (Ried, 1965). Increased respiration, by the mitochondria, which are found in vast numbers in the calicoblastic cells (Yamashiro and Yamazato, 1996), can provide ATP via oxidative phosphorylation for the active antiporters thereby enhancing calcification. Furthermore, some of the respiratory $\mathrm{CO}_{2}$ transforms to $\mathrm{HCO}_{3}^{-}$at the site of calcification and can be precipitated in the skeleton (Moya et al., 2008).

Prior to our experiments the corals were held at $6 \mathrm{~m}$ depth in the Gulf of Eilat, in that location corals are not chromatically acclimated to a specific waveband since penetration of all wavelengths between 400 and $700 \mathrm{~nm}$ is $\sim 70 \%$ of surface PAR (Levy et al., 2003, 2006). Photosynthetic pigments in isolated zooxanthellae did not show discrimination toward specific waveband (Halldal, 1968) therefore illuminating corals with narrow waveband, as seen under all treatments of this study, can lower the cumulative photosynthetic light collection as specific pigments in the antennae remain unexcited.

In general, calcification and photosynthesis of $P$. lutea and $A$. variabilis show a strong correlation (high $\mathrm{R}^{2}$ ) with increasing intensities of both control and blue light (Figure 4). However, while data points of white light show a slope below the 1:1 ratio (calcification $<$ photosynthesis) and this ratio decreases with light intensity (slopes are below 1), data points of both corals under blue light were significantly above the 1:1 ratio and this ratio increases with light intensity in $P$. lutea and is close to 1 in $A$. variabilis (Table 2). When rates of calcification and photosynthesis are similar (1:1 ratio), seawater $\mathrm{pH},{ }_{P} \mathrm{CO}_{2}$, and the $\mathrm{CaCO}_{3}$ saturation state all remain relatively unchanged. When calcification rate is higher than that of photosynthesis, as it was under blue light, the surrounding water and the coral tissues becomes acidic. However, this does not seem to slow calcification, at least under short incubations of $1 \mathrm{~h}$, and suggests that the $\mathrm{pH}$ modulation in the calcification site should be independent from photosynthesis. Our observations are based upon measurements of $\mathrm{O}_{2}$ and not $\mathrm{CO}_{2}$, however the relationship between photosynthesis and respiration of corals is based on a quotient of 1.1 (Muscatine et al., 1981). Furthermore, De Beer et al. (2000) showed with microelectrodes that in Favia sp. the dynamics of $\mathrm{O}_{2}$ production during light exactly correspond to these of $\mathrm{CO}_{2}$ uptake, and vice versa in the dark. As long as respiration rate exceeds that of photosynthesis, as under all intensities of blue light, any increase in photosynthesis only results in a slower accumulation of $\mathrm{CO}_{2}$ in the coral tissue. Even if under blue light there is some photosynthesis, the significant LEC under blue light was achieved despite an increase in $\mathrm{CO}_{2}$ concentrations in the coral tissue during the incubation. Even under control light, calcification of $P$. lutea begins to saturate at intensity $\left(\mathrm{E}_{\mathrm{k}}=\sim 110 \mu \mathrm{mol}\right.$ photons $\left.\mathrm{m}^{-2} \mathrm{~s}^{-1}\right)$ that is lower than the photosynthetic compensation $\left(E_{c}=170 \mu \mathrm{mol}\right.$ photons $\mathrm{m}^{-2}$ $\mathrm{s}^{-1}$ ) (Table 2).

We suggest that the short term (minutes to an hour) mechanism of LEC depends mainly on light activation of biologically mediated processes of the host (Figure 6). Nevertheless, photosynthesis may play a role in supporting that process. Mitochondria, which are found in high quantities in the calicoblastic epithelium, consume oxygen, and glycerol via respiration. This provides ATP that can be utilized by ATPase pumps. There are only a few studies demonstrating how metabolites are re-distributed across coral colonies; however, Taylor (1977) showed that photosynthetic energy is translocated to the fast growing areas of corals. In our study, blue LEC while respiration rate was higher than that of photosynthesis. In terms of the role of energy, our results suggest either that PSI reaction

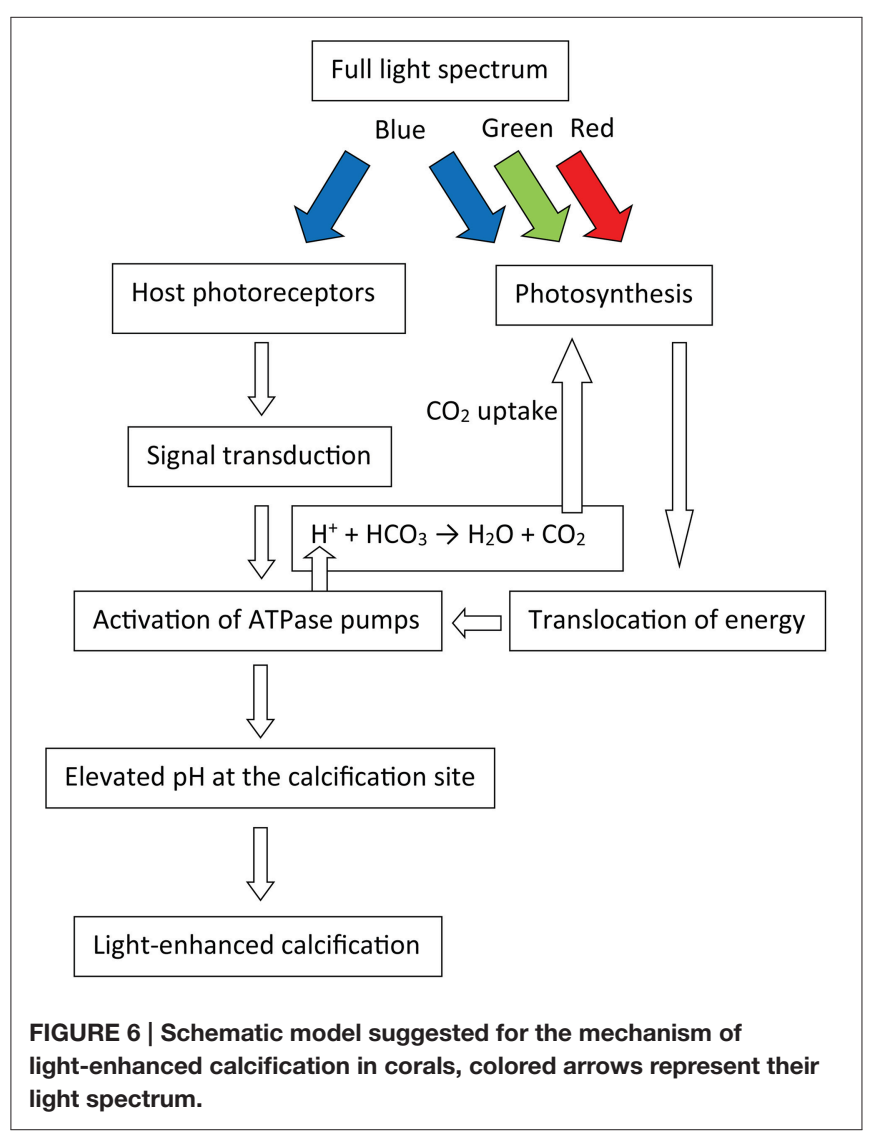


centers can utilize blue light for cyclic photophosphorylation or that the energy stores do not deplete in an hour of incubation. Al-Horani et al. (2007) showed that dark calcification of $G$. fascicularis decreases after about $6 \mathrm{~h}$, suggesting the depletion of such storages. However, calcification of $S$. pistillata was constant throughout $20 \mathrm{~h}$ of prolonged darkness (Moya et al., 2006). Since blue light may also have a role in synchronizing the corals' circadian rhythm, it is plausible that the corals use these light cues to synchronize calcification with photosynthetic carbon translocation during light hours. The effect of $\mathrm{CO}_{2}$ uptake on LEC may be secondary as most of the $\mathrm{pH}$ at the calcification site is controlled by the transporters, however the removed $\mathrm{H}^{+}$ion can react with $\mathrm{HCO}_{3}^{-}$and the $\mathrm{CO}_{2}$ product in the coelenteron may be utilized for photosynthesis (McConnaughey and Whelan, 1997). We note that dark calcification of bleached corals did increase from $\sim 0.6$ to $3 \mu \mathrm{mol} \mathrm{CaCO}_{3} \mathrm{~cm}^{-2} \mathrm{~h}^{-1}$ when supplied with glycerol and oxygen, suggesting that light activation is not the only process responsible for LEC. However, calcification of these bleached corals enhanced to $\sim 5 \mu \mathrm{mol} \mathrm{CaCO}_{3} \mathrm{~cm}^{-2}$ $\mathrm{h}^{-1}$ when illuminated without the addition of glycerol and/or oxygen (Colombo-Pallotta et al., 2010). This suggests that light absorption of the coral host may influence calcification more than photosynthetic energy input.

\section{CONCLUSIONS}

This study provides direct evidence that LEC in two species of important hermatypic corals (A. variabilis and $P$. lutea) can proceed at normal (or even slightly higher) rates while photosynthesis is below the compensation point. Such effect was previously shown only in Foraminifera under several DCMU concentrations (Erez, 1983; Ter Kuile et al., 1989a). Since $\mathrm{CO}_{2}$ concentrations in the coral tissues increase as these of $\mathrm{O}_{2}$ decrease, we suggest that $\mathrm{CO}_{2}$ uptake by the symbionts may

\section{REFERENCES}

Ahmad, M., Grancher, N., Heil, M., Black, R. C., Giovani, B., Galland, P., et al. (2002). Action spectrum for cryptochrome-dependent hypocotyl growth inhibition in Arabidopsis 1. 129, 774-785. doi: 10.1104/pp.0109 69.774

Al-Horani, F., Al-Moghrabi, S., and De Beer, D. (2003a). The mechanism of calcification and its relation to photosynthesis and respiration in the scleractinian coral Galaxea fascicularis. Mar. Biol. 142, 419-426. doi: 10.1007/s00227-002-0981-8

Al-Horani, F., Al-Moghrabi, S., and De-Beer, D. (2003b). Microsensor study of photosynthesis and calcification in the scleractinian coral, Galaxea fascicularis: active internal carbon cycle. J. Exp. Mar. Biol. Ecol. 288, 1-15. doi: 10.1016/S0022-0981(02)00578-6

Al-Horani, F. A., Tambutte, E., and Allemand, D. (2007). Dark calcification and the daily rhythm of calcification in the scleractinian coral, Galaxea fascicularis. Coral Reefs 26, 531-538. doi: 10.1007/s00338-007-0250-x

Allemand, D., Furla, P., and Bénazet-Tambutté, S. (1998). Mechanisms of carbon acquisition for endosymbiont photosynthesis in Anthozoa. Can. J. Bot. 76, 925-941. doi: 10.1139/cjb-76-6-925

Anctil, M., Hayward, D. C., Miller, D. J., and Ball, E. E. (2007). Sequence and expression of four coral $G$ protein-coupled receptors distinct from not be the primary reason for light-enhanced calcification. Long term contributions of the symbionts to LEC, as translocation of organic matrix building blocks, and other metabolites cannot be addressed from the $1 \mathrm{~h}$ long incubations of this study. Blue light photoreceptors, found in coral tissue, might be the link between light absorption by the coral host and activation of biological processes that enhance calcification under blue light (Figure 6). In order to understand the mechanisms of LEC it is necessary to explore the functions of these photoreceptors. If indeed, LEC could be decoupled from photosynthesis in corals, this would greatly advance our understanding of symbiotic relationship between coral and zooxanthellae, and would have important implications for understanding their co-evolution in addition to their role in the oceanic carbon cycle, and in the interpretation of paleoceanographic proxies (e.g., $\delta^{13} \mathrm{C}, \delta^{11} \mathrm{~B}$ ) in their skeletons.

\section{ACKNOWLEDGMENTS}

We are grateful to the reviewers and the editor for the helpful comments. Special thanks also to Ofri Mann for writing the hyperbolic tangent model and to Noa Moshkowitz for the statistical assistance, to Dana Nahum Cohen and to Or BenZvy for the assistance in data collection, to Jessy Bausell for revising the language and to Tanya Rivlin and Asaph Rivlin for providing important technical assistance. Also thanks to Prof. Oren Levy and Dr. Dan Tchernov for the scientific discussion and to the Interuniversity Institute in Eilat, Israel for supporting this study. This study was performed under permit No. 2012/38663 of the nature reservation authority of Israel and was supported by DFG German-Israeli-Palestinian trilateral research projectTRION II. We dedicate this work to the memory of Len (Leonard) Muscatine, a personal friend, pioneer of coral research, who inspired and taught all of us so much about science and originality. all classifiable members of the rhodopsin family. Gene 392, 14-21. doi: 10.1016/j.gene.2006.10.025

Assmann, S. M., Simoncini, L., and Schroeder, J. I. (1985). Blue light activates electrogenic ion pumping in guard cell protoplasts of Vicia faba. Nature 318, 285-287. doi: 10.1038/318285a0

Barnes, D. D. J. (1985). "The effect of photosynthetic and respiratory inhibitors upon calcification in the staghorn coral, Acropora formosa," in Proceedings of the 5th International Coral Reef Congress (Tahiti), 161-166.

Chalker, B., Carr, K., and Gill, E. (1985). "Measurement of primary production and calcification in-situ on coral reefs using electrode techniques," in Proceedings of the 5th International Coral Reef Congress (Tahiti), 167-172.

Chalker, B. E. (1976). Calcium transport during skeletogenesis in hermatypic corals. Comp. Biochem. Physiol. Part A Physiol. 54, 455-459. doi: 10.1016/03009629(76)90049-9

Chalker, B. E. (1981). Simulating light-saturation curves for photosynthesis and calcification by reef-building corals. Mar. Biol. 63, 135-141. doi: 10.1007/BF00406821

Cho, M. H., and Spalding, E. P. (1996). An anion channel in Arabidopsis hypocotyls activated by blue light. Proc. Natl. Acad. Sci. U.S.A. 93, 8134-8138. doi: 10.1073/pnas.93.15.8134

Cohen, I., and Dubinsky, Z. (2015). Long term photoacclimation responses of the coral Stylophora pistillata to reciprocal deep to shallow 
transplantation: photosynthesis and calcification. Front. Mar. Sci. 2:45. doi: 10.3389/fmars.2015.00045

Colombo-Pallotta, M. F., Rodríguez-Román, A., and Iglesias-Prieto, R. (2010). Calcification in bleached and unbleached Montastraea faveolata: evaluating the role of oxygen and glycerol. Coral Reefs 29, 899-907. doi: 10.1007/s00338-0100638-x

De Beer, D., Kühl, M., Stambler, N., and Vaki, L. (2000). A microsensor study of light enhanced $\mathrm{Ca}^{2+}$ uptake and photosynthesis in the reefbuilding hermatypic coral Favia sp. Mar. Ecol. Prog. Ser. 194, 75-85. doi: 10.3354/meps 194075

Enríquez, S., and Schubert, N. (2014). Direct contribution of the seagrass Thalassia testudinum to lime mud production. Nat. Commun. 5, 3835. doi: $10.1038 /$ ncomms 4835

Erez, J. (1983). "Calcification rates, photosynthesis and light in planktonic foraminifera," Biomineralization and Biological Metal Accumulation, eds P. Westbroek and E. W. De Jong (Springer), 307-312. doi: 10.1007/978-94-0097944-4_29

Fain, G. L., Hardie, R., and Laughlin, S. B. (2010). Phototransduction and the evolution of photoreceptors. Curr. Biol. 20, 114-124. doi: 10.1016/j.cub.2009.12.006

Falkowski, P. G., Dubinsky, Z., Muscatine, L., and Porter, J. W. (1984). Light and the bioenergetics of a symbiotic coral. Bioscience 34, 705-709. doi: $10.2307 / 1309663$

Furla, P., Galgani, I., Durand, I., and Allemand, D. (2000). Sources and mechanisms of inorganic carbon transport for coral calcification and photosynthesis. J. Exp. Biol. 203, 3445-3457.

Gao, K., Aruga, Y., Asada, K., Ishihara, T., Akano, T., and Kiyohara, M. (1993). Calcification in the articulated coralline alga Corallina pilulifera, with special reference to the effect of elevated $\mathrm{CO}_{2}$ concentration. Mar. Biol. 117, 129-132. doi: 10.1007/BF00346434

Gattuso, J. (1998). Effect of calcium carbonate saturation of seawater on coral calcification. Glob. Planet Change 18, 37-46. doi: 10.1016/S09218181(98)00035-6

Gattuso, J. P., Allemand, D., and Frankignoulle, M. (1999). Photosynthesis and calcification at cellular, organismal and community levels in coral reefs: a review on interactions and control by carbonate chemistry. Am. Zool. 39, 160-183. doi: $10.1093 / \mathrm{icb} / 39.1 .160$

Gattuso, J. P., and Buddemeier, R. W. (2000). Ocean biogeochemistry. Calcification and $\mathrm{CO}_{2}$. Nature 407, 311-313. doi: 10.1038/35030280

Gorbunov, M. Y., and Falkowski, P. G. (2002). Photoreceptors in the cnidarian hosts allow symbiotic corals to sense blue moonlight. Limnol. Oceanogr. 47, 309-315. doi: 10.4319/lo.2002.47.1.0309

Goreau, T. (1959). The physiology of skeleton formation in corals. I. A method for measuring the rate of calcium deposition by corals under different conditions. Biol. Bull. 116, 59-75.

Halldal, P. (1968). Photosynthetic capacities and photosynthetic action spectra of endozoic algae of the massive coral Favia. Biol. Bull. 134, 411-424. doi: 10.2307/ 1539860

Hilton, J. D., Brady, A. K., Spaho, S. A., and Vize, P. D. (2012). Photoreception and signal transduction in corals: proteomic and behavioral evidence for cytoplasmic calcium as a mediator of light responsivity. Biol. Bull. 223, 291-299. doi: $10.2307 / 41759020$

Iino, M. (1990). Phototropism: mechanisms and ecological implications. Plant. Cell Environ. 13, 633-650. doi: 10.1111/j.1365-3040.1990.tb01080.x

Ip, Y. K., Ching, B., Hiong, K. C., Choo, C. Y. L., Boo, M. V., Wong, W. P., et al. (2015). Light induces changes in activities of $\mathrm{Na}^{+} / \mathrm{K}^{+}$-ATPase, $\mathrm{H}^{+} / \mathrm{K}^{+}$-ATPase and glutamine synthetase in tissues involved directly or indirectly in lightenhanced calcification in the giant clam, Tridacna squamosa. Front. Physiol. 6:68. doi: 10.3389/fphys.2015.00068

Jones, L., and Myers, J. (1965). Pigment variations in anacystis nidulans induced by light of selected wavelengths. J. Phycol. 1, 7-14. doi: 10.1111/j.15298817.1965.tb04548.x

Kaniewska, P., Campbell, P. R., Fine, M., and Hoegh-Guldberg, O. (2009). Phototropic growth in a reef flat acroporid branching coral species. J. Exp. Biol. 212, 662-667. doi: 10.1242/jeb.022624

Khalil, M. T., and El-Rakman, N. S. A. (1997). Abundance and diversity of surface zooplankton in the Gulf of Aqaba, Red Sea, Egypt. J. Plankton Res. 19, 927-936. doi: 10.1093/plankt/19.7.927
Kinzie, R. A., Jokiel, P., and York, R. (1984). Effects of light of altered spectral composition on coral zooxanthellae associations and on zooxanthellae in vitro. Mar. Biol. 78, 239-248. doi: 10.1007/bf00393009

Kinzie, R., and Hunter, T. (1987). Effect of light quality on photosynthesis of the reef coral Montipora verrucosa. Mar. Biol. 94, 95-109. doi: 10.1007/BF00392902

Kuhl, M., Cohen, Y., Dalsgaard, T., Jorgensen, B., and Revsbech, N. (1995). Microenvironment and photosynthesis of zooxanthellae in scleractinian corals studied $\mathrm{pH}$ and light with microsensors for $\mathrm{0}_{2}, \mathrm{pH}$ and light. Mar. Ecol. Prog. Ser. 117, 159-172. doi: 10.3354/meps117159

Lee, K., and Yamamoto, H. (1968). Action spectra for light-induced de-epoxidation and epoxidation of xanthophylls in spinach leaf. Photochem. Photobiol. 7, 101-107. doi: 10.1111/j.1751-1097.1968.tb05834.x

Levy, O., Achituv, Y., Yacobi, Y. Z., Stambler, N., and Dubinsky, Z. (2006). The impact of spectral composition and light periodicity on the activity of two antioxidant enzymes (SOD and CAT) in the coral Favia favus. J. Exp. Mar. Biol. Ecol. 328, 35-46. doi: 10.1016/j.jembe.2005.06.018

Levy, O., Appelbaum, L., Leggat, W., Gothlif, Y., Hayward, D. C., Miller, D. J., et al. (2007). Light-responsive cryptochromes from a simple multicellular animal, the coral Acropora millepora. Science 318, 467-470. doi: 10.1126/science.1145432

Levy, O., Dubinsky, Z., and Achituv, Y. (2003). Photobehavior of stony corals: responses to light spectra and intensity. J. Exp. Biol. 206, 4041-4049. doi: 10.1242/jeb.00622

Lucas, J. M., and Knapp, L. W. (1997). A physiological evaluation of carbon sources for calcification in the octocoral Leptogorgia virgulata (Lamarck). J. Exp. Biol. 200, 2653-2662.

Marshall, A. T., and Clode, P. L. (2003). Light-regulated $\mathrm{Ca}^{2+}$ uptake and $\mathrm{O}_{2}$ secretion at the surface of a scleractinian coral Galaxea fascicularis. Comp. Biochem. Physiol. Part A 136, 417-426. doi: 10.1016/S1095-6433(03)00201-0

Marubini, F., and Thake, B. (1999). Bicarbonate addition promotes coral growth. Limnol. Oceanogr. 44, 716-720. doi: 10.4319/lo.1999.44.3.0716

Mason, B., Schmale, M., Gibbs, P., Miller, M. W., Wang, Q., Levay, K., et al. (2012). Evidence for multiple phototransduction pathways in a reef-building coral PLoS ONE 7:e50371. doi: 10.1371/journal.pone.0050371

Mass, T., Kline, D. I., Roopin, M., Veal, C. J., Cohen, S., Iluz, D., et al. (2010). The spectral quality of light is a key driver of photosynthesis and photoadaptation in Stylophora pistillata colonies from different depths in the Red Sea. J. Exp. Biol. 213, 4084-4091. doi: 10.1242/jeb.039891

McConnaughey, T. A., and Whelan, J. F. (1997). Calcification generates protons for nutrient and bicarbonate uptake. Earth Sci. Rev. 42, 95-117. doi: 10.1016/S0012-8252(96)00036-0

Moya, A., Tambutté, S., Bertucci, A., Tambutté, E., Lotto, S., Vullo, D., et al. (2008). Carbonic anhydrase in the scleractinian coral Stylophora pistillata: characterization, localization, and role in biomineralization. J. Biol. Chem. 283, 25475-25484. doi: 10.1074/jbc.M804726200

Moya, A., Tambutte, S., Tambutte, E., Zoccola, D., Caminiti, N., and Allemand, D. (2006). Study of calcification during a daily cycle of the coral Stylophora pistillata: implications for "light-enhanced calcification." J. Exp. Biol. 209, 3413-3419. doi: 10.1242/jeb.02382

Mueller, E. (1984). "Effects of a calcium channel blocker and an inhibitor of phosphodiesterase on calcification in Acropora formosa," in Proceedings of Advances in Reef Science (Miami, FL), 87-88.

Muscatine, L., McCloskey, L. R., and Marian, R. E. (1981). Estimating the daily contribution of carbon from zooxanthellae to coral animal respiration. Limnol. Oceanogr. 26, 601-611. doi: 10.4319/lo.1981.26.4.0601

North, W. J., and Pantin, C. F. A. (1958). Sensitivity to light in the sea-anemone Metridium senile (L): adaptation and action spectra. Proc. R. Soc. London B Biol. Sci. 148, 385-396. doi: 10.1098/rspb.1958.0032

Paasche, E. (1966). Action spectrum of coccolith formation. Physiol. Plant. 19, 770-779. doi: 10.1111/j.1399-3054.1966.tb07062.x

Passano, L. M., and McCullough, C. B. (1963). Pacemaker hierarchies controlling the behaviour of hydras. Nature 199, 1174-1175. doi: 10.1038/1991174a0

Pearse, V. B., and Muscatine, L. (1971). Role of symbiotic algae (zooxanthellae) in coral calcification. Biol. Bull. 141, 350-363. doi: 10.2307/1540123

Powell, D. W. (1981). Barrier function of epithelia. Am. J. Physiol. 241, G275-G288.

Ried, A. (1965). Transients of oxygen exchange in Chlorella caused by short light exposures. Annu. Rep. Dir. Dep. Plant Biol. 64, 399-406.

Rinkevich, B., and Loya, Y. (1984). Does light enhance calcification in hermatypic corals? Mar. Biol. 80, 1-6. 
Roberts, J. M., Wheeler, A. J., and Freiwald, A. (2006). Reefs of the deep: the biology and geology of cold-water coral ecosystems. Science 312, 543-547. doi: 10.1126/science. 1119861

Rocha, R. J. M., Silva, A. M. B., Fernandes, M. H. V., Cruz, I. C. S., Rosa, R., and Calado, R. (2014). Contrasting light spectra constrain the macro and microstructures of scleractinian corals. PLoS ONE 9:e105863. doi: 10.1371/journal.pone.0105863

Schneider, K., and Erez, J. (2006). The effect of carbonate chemistry on calcification and photosynthesis in the hermatypic coral Acropora eurystoma. Limnol. Oceanogr. 51, 1284-1293. doi: 10.4319/lo.2006.51.3.1284

Schürmann, P., Buchanan, B. B., and Arnon, D. I. (1972). Role of cyclic photophosphorylation in photosynthetic carbon dioxide assimilation by isolated chloroplasts. Biochim. Biophys. Acta 267, 111-124. doi: 10.1016/00052728(72)90143-0

Scott, B. D., and Jitts, H. R. (1977). Photosynthesis of phytoplankton and zooxanthellae on a coral reef. Mar. Biol. 41, 307-315. doi: 10.1007/BF00389097

Shimazaki, K., Doi, M., Assmann, S. M., and Kinoshita, T. (2007). Light regulation of stomatal movement. Annu. Rev. Plant Biol. 58, 219-247. doi: 10.1146/annurev.arplant.57.032905.105434

Shimazaki, K., Iino, M., and Zeiger, E. (1986). Blue light-dependent proton extrusion by guard-cell protoplasts of Vicia faba. Nature 319, 324-326. doi: $10.1038 / 319324 \mathrm{a} 0$

Slesak, I., Karpinska, B., Surówka, E., Miszalski, Z., and Karpinski, S. (2003). Redox changes in the chloroplast and hydrogen peroxide are essential for regulation of C3-CAM transition and photooxidative stress responses in the facultative CAM plant Mesembryanthemum crystallinum L. Plant Cell Physiol. 44, 573-581. doi: 10.1093/pcp/pcg073

Stambler, N. (1992). Harvesting and Utilization of Light by Hermatypic Corals. Ph.D. thesis, Bar-Illan University, RamatGan, Israel.

Stambler, N., and Dubinsky, Z. (2005). Corals as light collectors: an integrating sphere approach. Coral Reefs 24, 1-9. doi: 10.1007/s00338-004-0452-4

Stambler, N., and Shashar, N. (2007). Variation in spectral reflectance of the hermatypic corals, Stylophora pistillata and Pocillopora damicornis. J. Exp. Mar. Biol. Ecol. 351, 143-149. doi: 10.1016/j.jembe.2007.06.014

Stimson, J., and Kinzie, R. A. (1991). The temporal pattern and rate of release of zooxanthellae from the reef coral Pocillopora damicornis (Linnaeus) under nitrogen-enrichment and control conditions. J. Exp. Mar. Biol. Ecol. 153, 63-74. doi: 10.1016/S0022-0981(05)80006-1

Suggett, D. J., Dong, L. F., Lawson, T., Lawrenz, E., Torres, L., and Smith, D. J. (2013). Light availability determines susceptibility of reef building corals to ocean acidification. Coral Reefs 32, 327-337. doi: 10.1007/s00338-012-0996-7

Taddei-Ferretti, C., Di Maio, V., Musio, C., and Cotugno, A. (1992). Modulation of Hydra attenuata rhythmic activity. IV. Combined effects of background and pulse light wavelength. J. Photochem. Photobiol. B Biol. 15, 307-315. doi: 10.1016/1011-1344(92)85137-J

Taddei-Ferretti, C., and Musio, C. (2000). Photobehaviour of Hydra (Cnidaria, Hydrozoa) and correlated mechanisms: a case of extraocular photosensitivity. J. Photochem. Photobiol. B. 55, 88-101. doi: 10.1016/S1011-1344(00)00041-5

Tambutte, E., Allemand, D., Mueller, E., and Jaubert, J. (1996). A compartmental approach to the mechanism of calcification in hermatypic corals. J. Exp. Biol. 199, 1029-1041.

Tambutté, E., Tambutté, S., Segonds, N., Zoccola, D., Venn, A., Erez, J., et al. (2012). Calcein labelling and electrophysiology: insights on coral tissue permeability and calcification. Proc. R. Soc. Lond. B Biol. Sci. 279, 19-27. doi: 10.1098/rspb.2011.0733

Taylor, A. R., Chrachri, A., Wheeler, G., Goddard, H., and Brownlee, C. (2011). A voltage-gated $\mathrm{H}^{+}$channel underlying $\mathrm{pH}$ homeostasis in calcifying coccolithophores. PLoS Biol. 9:e1001085. doi: 10.1371/journal.pbio.1001085
Taylor, D. (1977). "Intra-colonial transport of organic compounds and calcium in some Atlantic reef corals," in Proceedings of the 3rd International Coral Reef Symposium (Miami, FL).

Ter Kuile, B., Erez, J., and Padan, E. (1989a). Competition for inorganic carbon between photosynthesis and calcification in the symbiont-bearing foraminifer Amphistegina lobifera. Mar. Biol. 259, 253-259.

Ter Kuile, B., Erez, J., and Padan, E. (1989b). Mechanisms for the uptake of inorganic carbon by two species of symbiont-bearing foraminifera. Mar. Biol. $251,241-251$.

Vandermeulen, J. H., Davis, N. D., and Muscatine, L. (1972). The effect of inhibitors of photosynthesis on zooxanthellae in corals and other marine invertebrates. Mar. Biol. 16, 185-191.

Vize, P. D. (2009). Transcriptome analysis of the circadian regulatory network in the coral Acropora millepora. Biol. Bull. 216, 131-137.

Wagner, D., Przybyla, D., Op den Camp, R., Kim, C., Landgraf, F., Lee, K. P., et al. (2004). The genetic basis of singlet oxygen-induced stress responses of Arabidopsis thaliana. Science 306, 1183-1185. doi: 10.1126/science. 1103178

Wijgerde, T., Henkemans, P., and Osinga, R. (2012a). Effects of irradiance and light spectrum on growth of the scleractinian coral Galaxea fascicularisApplicability of LEP and LED lighting to coral aquaculture. Aquaculture 344, 188-193. doi: 10.1016/j.aquaculture.2012.03.025

Wijgerde, T., Jurriaans, S., Hoofd, M., Verreth, J. A. J., and Osinga, R. (2012b). Oxygen and heterotrophy affect calcification of the scleractinian coral Galaxea fascicularis. PLoS ONE 7:e52702. doi: 10.1371/journal.pone. 0052702

Winkler, L. W. (1888). Die Bestimmung des im Wasser gelösten Sauerstoffes. Ber. Dtsch. Chem. Ges. 21, 2843-2854. doi: 10.1002/cber.1888021 02122

Wolken, J., and Mogus, M. (1979). Extra-ocular photosensitivity. Phptochem. Photobiol. 29, 189-196. doi: 10.1111/j.1751-1097.1979.tb09281.x

Yamamoto, H. Y., Chang, J. L., and Aihara, M. S. (1967). Light-induced interconversion of violaxanthin and zeaxanthin in New Zealand spinachleaf segments. Biochim. Biophys. Acta 141, 342-347. doi: 10.1016/03044165(67)90108-0

Yamashiro, H., and Yamazato, K. (1996). Morphological studies of the soft tissues involved in skeletal dissolution in the coral Fungia fungites. Coral Reefs 15, 177-180. doi: 10.1007/s003380050039

Yarfitz, S., and Hurley, J. B. (1994). Transduction mechanisms of vertebrate and invertebrate photoreceptors. J. Biol. Chem. 269, 14329-14332.

Zeiger, E., Iino, M., Shimazaki, K. I., Ogawa, T., Farquhar, G. D., and Cowan, I. R. (1987). The Blue-light Response of Stomata: Mechanism and Function. California, CA: Stanford University Press.

Conflict of Interest Statement: The authors declare that the research was conducted in the absence of any commercial or financial relationships that could be construed as a potential conflict of interest.

The Associate Editor, Dr. Stambler, declares that, despite being affiliated to the same institution as the author, Prof. Dubinsky, the review process was handled objectively and no conflict of interest exists.

Copyright (c) 2016 Cohen, Dubinsky and Erez. This is an open-access article distributed under the terms of the Creative Commons Attribution License (CC BY). The use, distribution or reproduction in other forums is permitted, provided the original author(s) or licensor are credited and that the original publication in this journal is cited, in accordance with accepted academic practice. No use, distribution or reproduction is permitted which does not comply with these terms. 